\title{
Promotion of Freight Mobility in Milan: Environmental, Energy and Economical Aspects
}

\author{
P. Menga ${ }^{1}$, R. Buccianti ${ }^{1}$, M. Bedogni ${ }^{2}$, S. Moroni ${ }^{2}$ \\ ${ }^{I}$ CEI-CIVES, Milan-Italy, CIVES@ceiweb.it \\ ${ }^{2}$ AMAT, Milan-Italy, marco.bedogni@amat-mi.it
}

\begin{abstract}
In order to improve air quality in the Controlled Traffic Zone "Area C" of Milan, in addition to the rules already in force, two topics now under consideration by the municipality are the increase of car-sharing and measures to stimulate the use of electric vehicles, including their adoption for the last-mile delivery of goods. The paper presents the evaluation of the potential benefits of electric vehicles, in particular for the case of goods delivery.

Comparisons to present i.c.e. based vehicles are presented in terms of economical aspects (from the point of view of the end user and of the Country), energy consumption and pollution impact (both local and global). Also the contribution to costs and pollution of two-wheels motor vehicles is taken into consideration in order to give a more complete overview of the different traffic segments.
\end{abstract}

Keywords: logistic, sustainable mobility, goods delivery

\section{Introduction}

Several road traffic regulations have already been implemented to improve air quality in the city of Milan, in particular a private traffic restriction scheme in the inner part called "Area C", and a set of measures favourable to sustainable mobility over the entire town.

Within "Area C", which extends over about 10 square kilometres, the circulation of gasoline vehicles Euro 0 and diesel vehicles pre-Euro 4 is prohibited, while a daily fee is applied to diesel Euro 4 to Euro 6 and to gasoline vehicles Euro 1 to Euro 6. The 43 access points to the area are controlled by cameras to recognise automatically the plate of each vehicle. Data are transmitted in realtime to a control system connected to the national vehicles register, which allows an immediate classification of vehicles and permits also the automatic payment of the entrance fee.

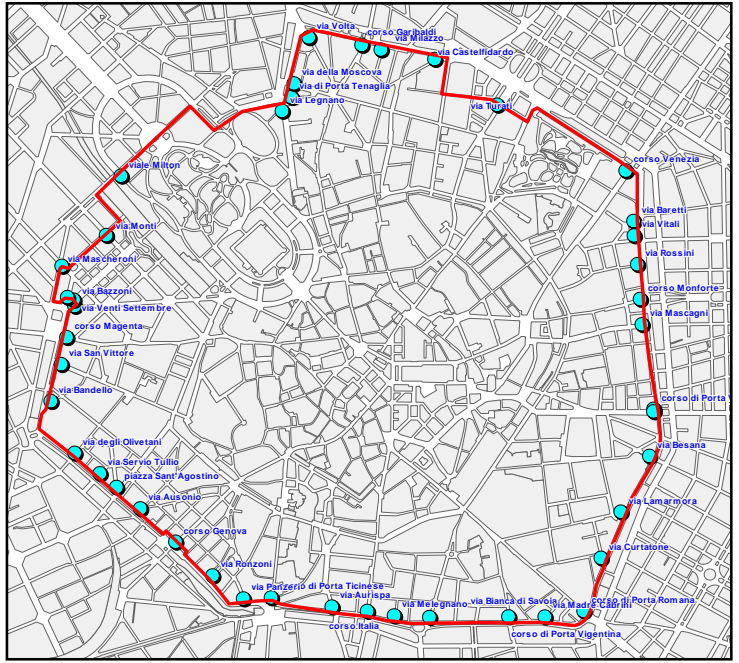

Fig. 1 - Milan Area C

One year after its implementation, Area C confirmed to be a strong tool to reduce road traffic flows. In fact, the number of entrances of private motor vehicles into Area C (cars, vans and 2 -wheels) has been reduced by $31 \%$ 
(from about 148,000 to 103,000 ); moreover, Area C rules drastically decreased high emitters of atmospheric pollutants and increased the use of low impact vehicles: on average, $12 \%$ of private cars and duty vehicles now entering this area are hybrid, LPG or CNG and electric, and traffic emissions decreased for all pollutants (for $\mathrm{CO}_{2}-35 \%$ ). Also, specific monitoring campaigns of the concentration of airborne particulate Black Carbon (BC) show an important decrease as compared to the outside area, ranging from $-28 \%$ at residential sites in winter season to $-52 \%$ at kerbside sites in summer. This pollutant is considered a good indicator for the toxicity of traffic emissions exposure, thus the observed differences mean a remarkable reduction in related expected mortality and morbidity for citizens and city users [4].

\subsection{Further steps towards good air quality}

In order to further improve the air quality, the two chief topics now under consideration by the municipality are the increase of the car-sharing, and measures to stimulate the recourse to electric vehicles. The first one car sharing - is aimed at the introduction of the "one-way" model, starting with 132 cars and with the objective of reaching in the end 600 to 2,000 cars. The system would be set up and managed by private operators that should pay to the municipality an annual fee per each i.c.e. car, but no fee for electric cars. In the framework of the initiatives related to the worldwide event "Expo Milano 2015", the setting up of technological platforms named "digital islands" is also in progress, within a smart-city vision that include multimedial services, wi-fi, smart lighting and, together with the bike sharing already widespread all over the town (with conventional bikes), also the sharing of electric quadricycles. The first 15 digital islands will be ready by the end of the year, with a fleet of 60 quadricycles.

Other measures are already in force in favour of electro-mobility, like the exemption of electric vehicles from the daily fee to access Area $\mathrm{C}$, and their free parking in pay parking areas over the entire town. In addition, the municipality has issued a detailed guideline for the concession, at a very favourable economic conditions, for the installation of recharging infrastructure in public areas. At the moment the business model for the recharge is that of service providers in competition. Support is also foreseen for the installation of recharge stations inside underground and multi-storey private parkings.

As a whole, these measures clearly show an overall view favourable to electro-mobility.

To further improve the use of zero-emission vehicles, additional interventions are at present under consideration, aimed at encouraging the gradual recourse to electric vehicles for the last-mile delivery of goods.

\section{Towards a Freight Electric Mobility}

\subsection{The UE project FR-EVUE}

Project FR-EVUE aims at implementing and demonstrating the adoption of electric vehicles for the freight delivery, and involves 8 towns (Stockolm, Rotterdam, Oslo, Milan, Madrid, London, Lisbon and Amsterdam). The focus of Milan is on the identification of an innovative pattern for urban logistics in the pharmaceutical supply chain. The system will be based on the use of ICT technologies for an Intelligent Transport System (ITS) and on the realization of a logistic hub ("Nearby Delivery Area"), served by electric vehicles for the last mile delivery. The use of ITS contributes to real-time traffic management, reducing delivery times and congestion. In addition to reducing polluting emissions, electric trucks would reduce as well noise, allowing their use also at night.

The project, still in the design phase at the date of writing present paper, will provide for the realization of a demonstrative system to be tested in Area C.

\subsection{Evaluation of Global Benefits of Electric Mobility}

In order to evaluate quantitatively the potentialities for further improvement of the air quality, and to derive the proper public support to be addressed at the different topics, an analysis has been carried out on a number of segments of mobility (individual cars, goods delivery, two-wheelers, etc.), by evaluating for each of them, in the current situation, the local and greenhouse emissions, the primary energy consumption, and the monetary impact of all these externalities, as perceived respectively by the society (national balance of payment) and by the end users. After that, for the same segments of mobility, the potential effect of 
the replacement of present vehicles with electric and hybrid plug-in vehicles has been worked out, evaluating the same impact parameters.

The analysis has been performed on the existing i.c.e. vehicle population circulating inside Milan Area $\mathrm{C}$, where a detailed monitoring of all the accesses is available. Of course many results can be easily extrapolated to the entire Milan territory and other urban situations.

\section{Results of the evaluations}

\subsection{Private cars and freight delivery}

The total population of cars moving daily into Area C decreased from 105,000 to about 65,000 since the entry into force of Area C rules. On the contrary, the delivery vans decreased only slightly (from 13,700 to 11,600 ), showing the well known rigidity of this segment of road mobility.

The number of these delivery vehicles exhibit a payload mostly ranging from about 400 to about $1,500 \mathrm{~kg}$ and a corresponding engine power from about 60 up to $140 \mathrm{~kW}$.

Most of them (about $70 \%$ ) are diesel vans but, as previously stated, the rules of area $\mathrm{C}$ acted to increase to some extent the number of "cleaner" non-electric vehicles (CNG, LPG).

The analysis of the total daily mileage (from the origin of the trip, to the return at the same point after the service) is on average about $36,8 \mathrm{~km}$, and the frequency distribution shows that $95 \%$ of the cases fall within $100 \mathrm{~km}$, thus within the capability of to-day electric vans.

Therefore, the implementation of electric mobility of goods could be started in principle also without modifying present logistic organization (without delivery platforms), by simply substituting, gradually, present i.c.e. delivery vans with electric ones. The appearance on the market of plug-in electric vans would permit an even larger application to freight transportation, maintaining the advantage of last-mile zero emission.

The recharge of batteries could be done mainly overnight, within the fleet companies facilities, without the need of a significant public recharge infrastructure in the city area, which would be accessed as a complementary system.

Therefore, this scenario (the entire fleet totally replaced by electric or plug-in vehicles) was used for all impact evaluations, as an image of the extreme case.

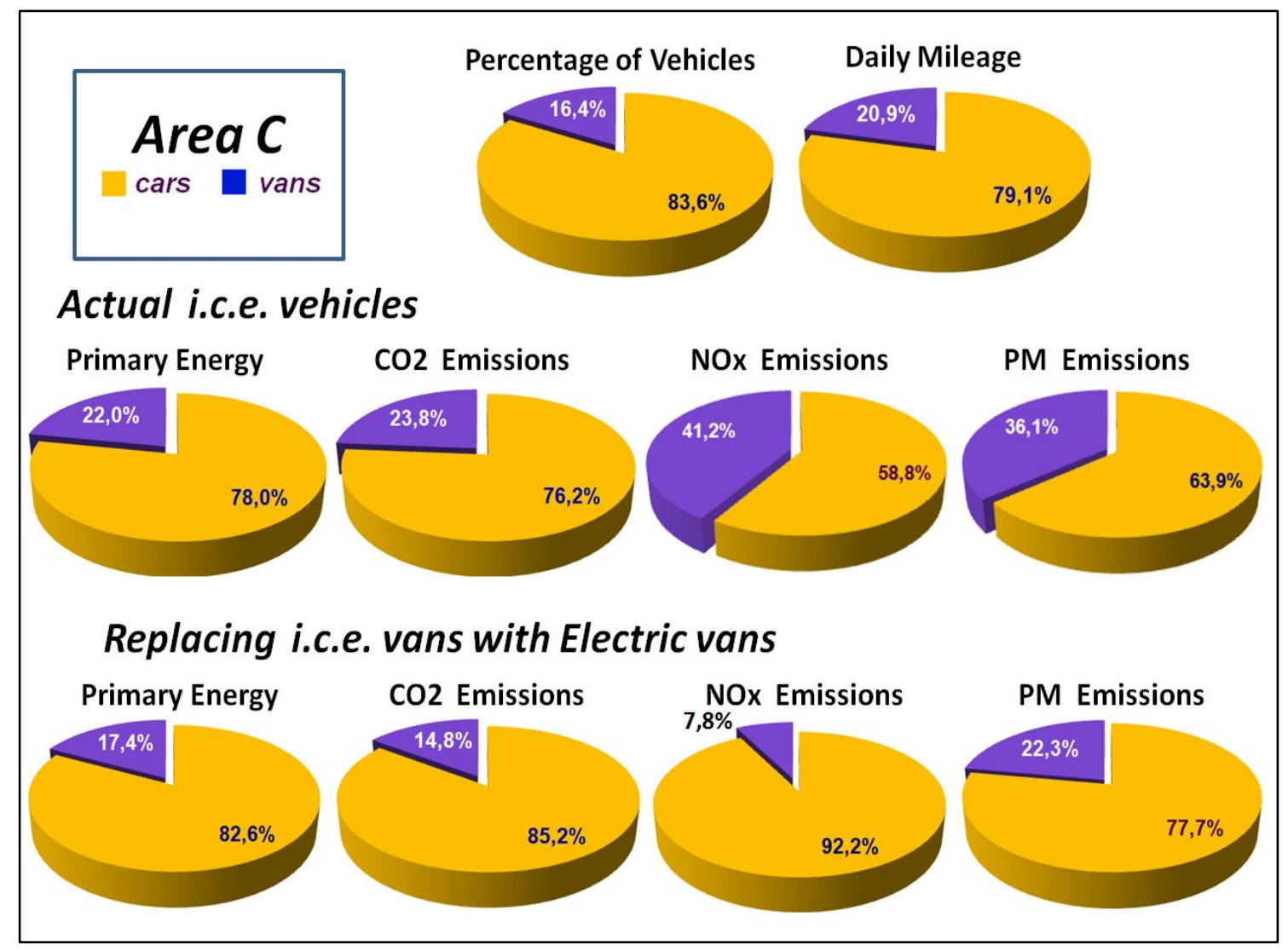

Fig. 2 - Global and local impact of vehicles circulating in Area C 
Figure 2 at previous page summarizes the basic input data (number of vehicles and their daily mileage) and the main environmental results (primary energy, $\mathrm{CO}_{2}$ emission, local $\mathrm{PM}$ and NOx emissions).

As expected, the introduction of electric vans shows a very important benefit, much higher than the ratio between their population and the total population. This is due to the cumulative effect of their higher daily mileage, their larger size and consumption in respect of those of cars, and their higher average age that translates into higher local emissions (older Euro categories).

The economical evaluation of these issues has been done at the country level, considering the following items:

$>$ Primary energy imported by the country (affecting the balance of payment)

$>$ External cost due to the bad local air quality (health cost sustained by the society)

$>$ External cost for the impact on the ecosystem (acid rain, degradation of buildings and architectures)

$>$ Monetary value of the $\mathrm{CO}_{2}$ emission (according to UE estimates).

Of course these different items are not basically homogeneous, but all of them do represent a bad way to waste the country monetary resources, and in this sense they can be summed up in order to give an overall picture of the country cost for the different mobility paradigms. Thus, this "overallcountry-cost" can be an effective indicator to define and address mobility policies.

As a first approximation, the economical influence of acoustical noise has not taken into account.

The detailed value assumed for each economical parameter is as follows in table 1 .

Table1: External costs assumed

\begin{tabular}{|c|ll|}
\hline Pollutant & \multicolumn{2}{|c|}{ Cost } \\
\hline $\mathrm{CO}$ & $0,0032 € / \mathrm{g}$ & {$[5]$} \\
\hline $\mathrm{HC}$ & $0,002 € / \mathrm{g}$ & {$[5]$} \\
\hline $\mathrm{NOx}$ & $0,0088 € / \mathrm{g}$ & {$[5]$} \\
\hline $\mathrm{PM}$ exhaust & $0,418 € / \mathrm{g}$ & {$[5]$} \\
\hline $\mathrm{PM}$ non-exhaust & $0,209 € / \mathrm{g}$ & {$[5]$} \\
\hline $\mathrm{CO}_{2}$ & $40 € /$ ton & {$[6]$} \\
\hline $\mathrm{NOx}_{2}$ (global) & $0,00018 € / \mathrm{g}$ & {$[5]$} \\
\hline $\mathrm{SO}_{2}$ (global) & $0,005 € / \mathrm{g}$ & {$[5]$} \\
\hline
\end{tabular}

As regards electric vehicles, the evaluations have been carried out assuming that the mix of primary energy used for their recharge is the same as the yearly average of today Italian electricity generation system; this is equivalent to assuming that the recharge takes places roughly for about $50 \%$ overnight and for $50 \%$ in daytime.

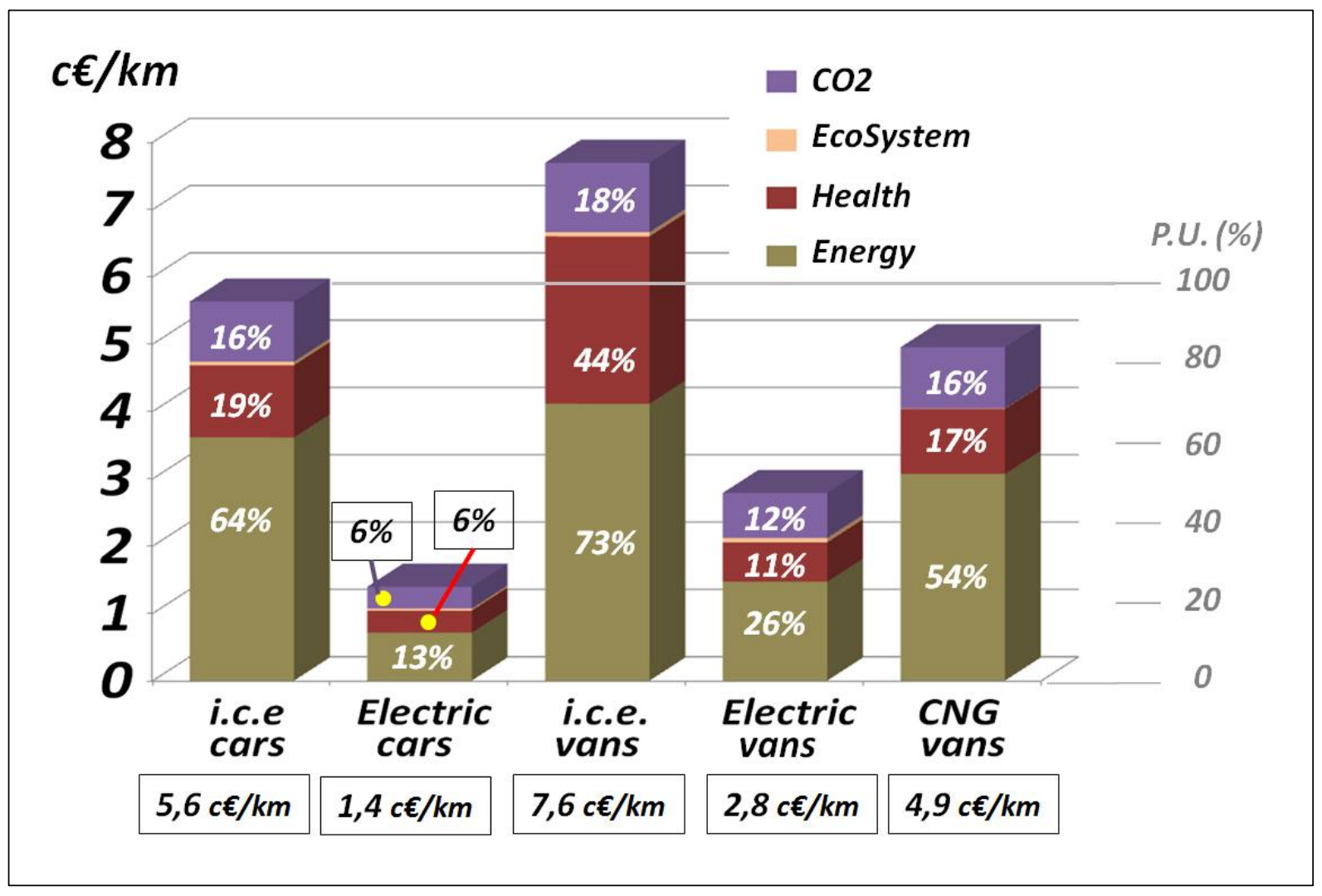

Fig. 3 - Cost for the Country of the different vehicle technology 
Fig. 3 at previous page summarizes the results of these economical evaluations, expressed in terms of cost per kilometre that the Country sustains for the different types of vehicles.

For the sake of comparison, also CNG vehicles have been included, due to their good environmental performance, that in principle could place them as competitors of electromobility. In the figure, all the percentages are expressed with reference to the total cost/kilometre of the i.c.e. car.

A quite unexpected result is that, in economical terms, $\mathrm{CO}_{2}$ emissions, which are normally perceived as the most significant indicator for the quality of mobility, and even the cost of externalities sustained by the society for the health diseases due to local pollution, play a role much lower than that of the cost of the energy sources used and imported to supply the vehicles. Electric vehicles appears clearly much less expensive. The huge gap between i.c.e. vehicles and electric ones is due both to the their higher overall efficiency and the lower cost of the primary energy sources used for the generation of electricity (which takes into account as well the import of nuclear electricity from abroad, and renewable sources like hydroelectric, wind and solar energy). CNG vans have as well economical advantages in respect to diesel vans, but remain quite far from electric ones.

On these bases, the overall monetary cost (for the Country) for the whole fleet of cars and vans circulating within Area $\mathrm{C}$ has also been calculated and is reported in fig. 4, expressed in Per-Unit (P.U.) assuming the case of today total i.c.e. vehicles $(65,000$ vans and 12,000 cars) as the Base $=1$ (first bar). Again, the contribution of vans appears much higher than their numerical population.

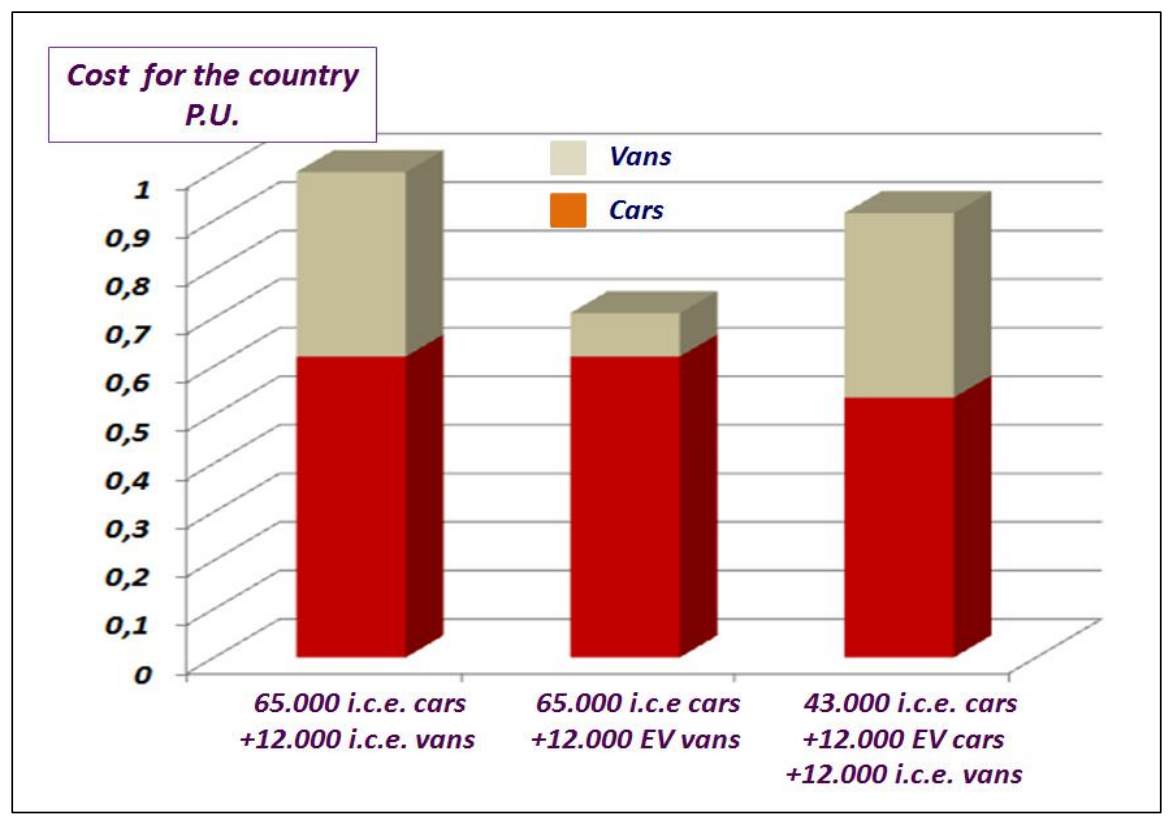

Fig. 4 - Cost for the Country of the complete fleet moving in Area C

The second bar represents the case of the total replacement of i.c.e. vans with electric ones, and confirm as expected a very good improvement.

The big potential advantage of introducing electric vehicles in the domain of commercial fleet vehicles like freight delivery, is given even more clearly by the third bar of the figure, that reports the case of substituting again a population of 12,000 i.c.e. vehicles, but in this case cars instead of vans. In this case the benefit is much lower, due to the shorter length of the car trips and their lower specific consumption and emissions.

As already said, starting the implementation of electric freight mobility could be done without intervening immediately on the logistic chain, by simply substituting, gradually, present i.c.e. vehicles with electric ones, as the study has shown that the daily mileage of most vehicles working for goods delivery in Area $\mathrm{C}$ falls within the capabilities of electric vehicles.

However, the high capital cost of electric vehicles in the present phase is not fully balanced by their lower energy cost, as the others items of running cost remain high (yearly taxes, insurance, maintenance, etc.). Therefore, the resulting Total Cost of Ownership (TCO) remains slightly higher than that of today diesel fleet, as reported in fig. 5. 
In addition, the higher high initial cost of electric vehicles does remain also psychologically a big deterrent to the decision of purchase by the end user.

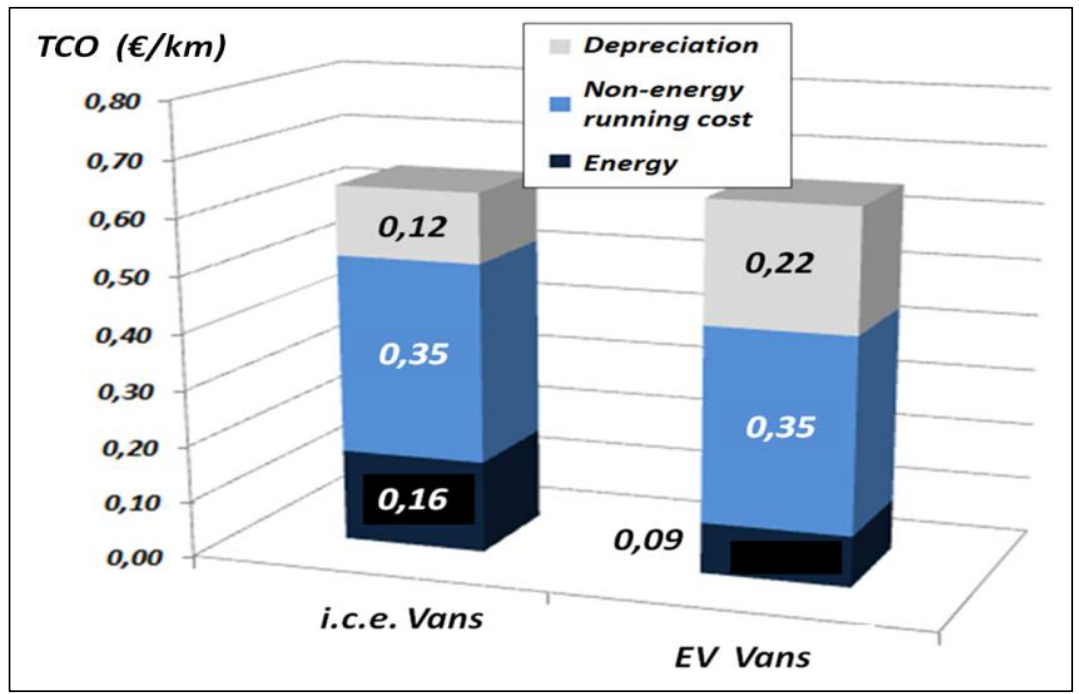

Fig. 5 - TCO of diesel and electric vans

Therefore, in order to start the introduction of goods electro-mobility, it is necessary to identify and adopt incentive measures, aimed at reaching easily the balance and remove the unavoidable initial reluctance.

These measures could be both economical (mainly at national level), but also of regulatory nature at municipality level, that would translate as well into economical advantage for the fleet owners. An example is already in force in Milan, where the access to Area $\mathrm{C}$ is free for electric vehicles. Some European towns extend largely the allowed timetable for the goods delivery when the service is carried out by means of electric vehicles.
At the time of writing this paper, the results of the present analysis are under evaluation by the Municipality of Milan, and local facilitations and further regulatory measures are currently under study in order to increase the use of electric duty vehicles.

\subsection{Two-wheels motor vehicles}

Additional evaluations have been done for the complete fleet of present i.c.e. vehicles circulating inside Area $\mathrm{C}$. The chief results are reported in the bar diagrams of fig. 6 , which gives a picture of the relative contribution of the different categories of vehicles (2-wheels i.c.e. vehicles, cars, vans) to

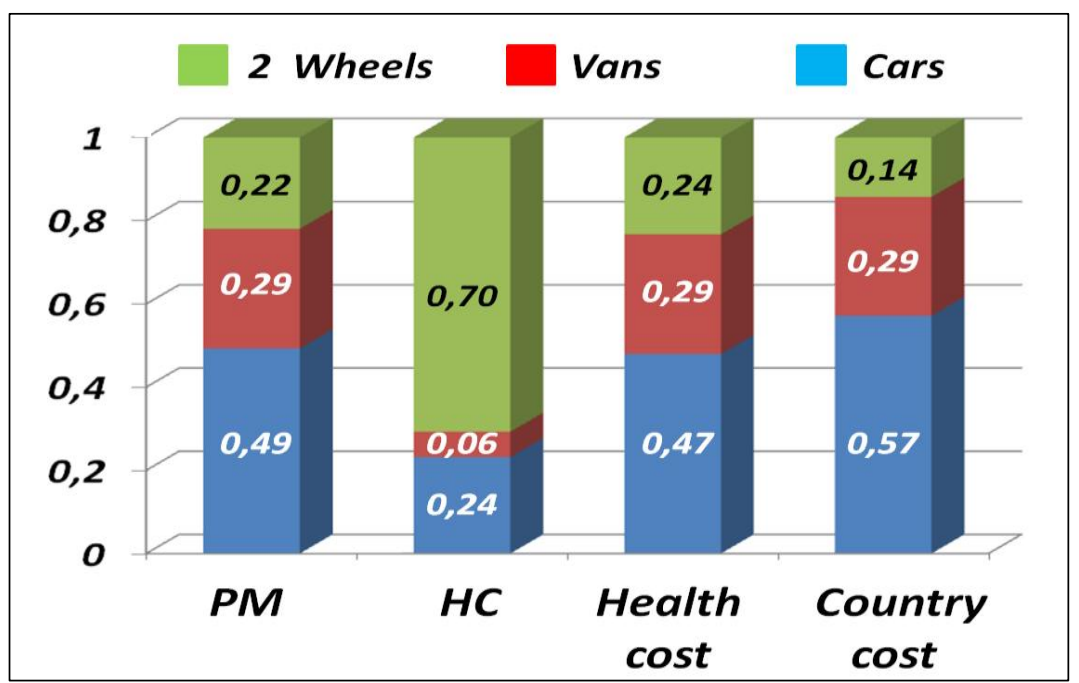

Fig. 6 - Impact of the complete population of i.c.e. vehicles circulating in Area C 
the total emissions of Particulate and Hydrocarbons, to the total cost sustained by the country for their local pollution, and to the overall country cost as previously described. It may be surprising the large impact of two-wheels (about 12,000 out of a total population of 103,000 vehicles), mainly due to the existence of a large number of old technologies scooters and mopeds still in circulation. At the same time, these results suggest the potentialities for significant further improvement of air quality and cost, that would arise from the introduction of electric mopeds and scooters.

Detailed evaluations on this topic are in progress.

\section{Conclusions}

Further in-depth assessments are in progress in order to define the actual actions to be carried out in order to involve the different stakeholders, in particular vehicle producers and freight operators, and define a road map to gradually translate the described potentialities into reality.

\section{References}

[1] P. Menga and R. Buccianti: "Benefit Evaluation of Electric Vehicles in Specific Areas: A case of Freight Fleets"; EVER Monaco, 2011

[2] P. Menga, "Behind the words "Sustainable vehicles". Conference on Sustainable Development - A Challenge for European Research, UE Commission, Brussels 2009.

[3] P. Menga and M. Ceraolo, "An Evaluation of Global Environment and Energy Value of Vehicle Technology". EET-2008, Geneve, 2008

[4] G. Invernizzi G., S. Moroni, A. Ruprecht, G. Tosti, M. Bedogni, B. Villavecchia, C. Sioutas and D. Westerdahl: "The Black Carbon monitoring project of 'Area C', the new Milan city center traffic restriction zone. Results of the 2012 wintertime campaign at urban residential sites". $16^{\text {th }}$ ETH Conference on 'Combustion Generated Nanoparticles', Zurich, June 24-27th, 2012.

[5] Authors by CE Delft, INFRAS and Fraunofer ISI: "External Cost of Transport in Europe - Update Studi for 2008". Publication code: 11.4215 .50

[6] Directive 2009/33/CE of European Parliament and Council, "Promotion of clean and low consumption vehicle for road transport", 23 April 2009.

\section{Authors}

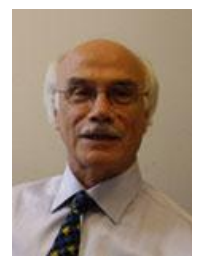

\section{Pietro Menga}

President of CIVES (the Italian AVERE Section) and VicePresident of AVERE. Formerly, vice responsible of the Department "Rational End-Use of Energy" within the Research Centre of the Italian Electricity Board. Member of national and international committees in the field of road transport, of energy, and of related technologies.

\section{Roberto Buccianti}

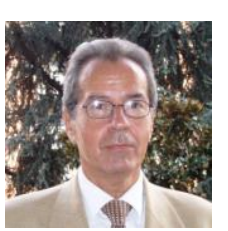

Business Consultant, Auditor for research activities in electro-energy field and Auditor for Quality assessment in University. Chairman of the Italian UNI-CEI Joint Commission "Metrology" and Secretary of Italian Technical Committee CEI TC 85/66 "Measuring equipments for Measurement, Control and Laboratory use". Member of CIVES

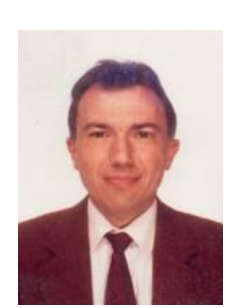

\section{Marco Bedogni}

Physics Degree with subsequent specialisation in air pollution and meteorology modelling \& data management. Current activities: development and application of mathematical models as Decision Support for the Municipality of Milan.

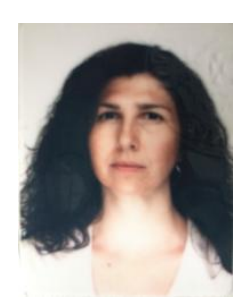

\section{Silvia Moroni}

$\mathrm{PhD}$ in Environmental Engineering with specialisation in air pollution and vehicular emissions.

Current activities: air quality assessment of planned measures/new technologies for the Municipality of Milan, with focus on health effects. 